\title{
Openness and topic avoidance in interpersonal communication about ovarian cancer: An uncertainty management perspective
}

\author{
Dinah A. Tetteh, ${ }^{1}$ Najma Akhther ${ }^{2}$ \\ ${ }^{1}$ Department of Communication, Arkansas State University, Jonesboro, Arkansas; ${ }^{2}$ Department of Communication, Wayne State \\ University, Detroit, Michigan, USA
}

\begin{abstract}
\end{abstract}
This study examined openness and topic avoidance in interpersonal communication about ovarian cancer. Guided by the uncertainty management theory, the researchers analyzed qualitative data from 28 ovarian cancer patients/survivors and found openness and topic avoidance to be complex communication behaviors which are connected to patients/survivors' uncertainty. Participants appraised uncertainty about disease prognosis and effectiveness of treatments as a threat; thus, they avoided topics such as treatment side effects and fears about death and disease recurrence to manage such uncertainty. Furthermore, findings showed that communication about ovarian cancer is layered with degrees of openness and avoidance relative to respective audiences and changing illness trajectories. Overall, the findings indicate connections between interpersonal communication about ovarian cancer and uncertainty management practices, suggesting that intervention efforts should help cancer patients/survivors and relational others practice sensitivity when discussing topics such as death and dying.

Keywords: Communication; openness; ovarian cancer; topic avoidance; uncertainty.

Contributions: DT conceived the idea for the project, collected and analyzed data, and also wrote the manuscript. NA assisted with data analysis and writing of the manuscript.

Conflict of interests: The authors declare no conflict of interest.

Further information: The article was presented at the 2019 National Communication Association convention held in Baltimore, MD. Data for this study were collected at Bowling Green State University, where the first author received her $\mathrm{PhD}$, while the article was written at Arkansas State University, where she is an assistant professor and the second author was a graduate student.

Availability of data and materials: All data generated or analyzed during this study are included in this published article.

Ethics approval and consent to participate: The Ethics Committee of Bowling Green State University, Bowling Green, $\mathrm{OH}$ approved this study (ethics approval 686884). The study is conformed with the Helsinki Declaration of 1964, as revised in 2013, concerning human and animal rights. All patients participating in this study signed a written informed consent form for participating in this study.

Informed consent: Written informed consent was obtained from a legally authorized representative(s) for anonymized patient information to be published in this article.

Received for publication: 29 September 2020.

Revision received: 20 October 2021.

Accepted for publication: 22 November 2021.

This work is licensed under a Creative Commons Attribution NonCommercial 4.0 License (CC BY-NC 4.0).

${ }^{\circ}$ Copyright: the Author(s), 2021

Licensee PAGEPress, Italy

Qualitative Research in Medicine \& Healthcare 2021; 5:9376

doi:10.4081/qrmh.2021.9376

\section{Introduction}

A cancer diagnosis is an unexpected life event producing fear and uncertainty in those affected. Ovarian cancer patients/survivors experience significant levels of uncertainty because of unspecified disease symptoms (e.g., gas, bloating and constipation), late-stage diagnosis (i.e., stages III or IV), severe treatment side effects (e.g., neuropathy), high recurrence rate, ${ }^{1-4}$ and also because treatment does not guarantee cure. ${ }^{1}$ In addition to that, location of the ovaries and fallopian tubes (i.e., primary organs associated with ovarian cancer) in the interior of the female body have contributed to seeming invisibility of the disease $^{5}$ and impacted how affected women communicate about and respond to risk and actual disease. ${ }^{6}$

Research suggests that ovarian cancer patients/survivors manage disease-related uncertainty by avoiding negative information and individuals with worse disease symptoms. ${ }^{4,7}$ Similar research by Manne and colleagues ${ }^{8}$ also reveals that gynecologic cancer survivors, including ovarian cancer survivors, avoid disclosing concerns pertaining to death, disease progression, and sexual functioning to family and friends. ${ }^{8}$ These research findings focus on topic avoidance (TA) among ovarian cancer patients/survivors, given that concerns about death and recurrence are common among this population. ${ }^{9}$ Women diagnosed with late-stage ovarian cancer do not openly express concerns about physical and emotional symptoms in order to protect loved ones who may be in denial about disease prognosis, meaning there is often informal care- 
giver denial and lack of patient disclosure at the end-stage of the disease. ${ }^{10}$ The need to protect loved ones is also a reason why ovarian cancer survivors sometimes disclose disease-related concerns to friends instead of family members. ${ }^{4}$ Lack of open communication can negatively impact survivors' relational quality ${ }^{1}$ and lead to psychological distress in survivors (e.g., anxiety and depression). ${ }^{10}$

Dale Brashers' uncertainty management theory $(\mathrm{UMT})^{11}$ has been used in the analysis of patient experiences in health care and medical settings, including the experiences of people with acute and chronic illnesses (e.g., cancer and diabetes) $)^{12,13}$ and those predisposed to certain cancers. ${ }^{14}$ Thus, the theory is an appropriate framework to use to investigate communication challenges experienced by ovarian cancer patients/survivors and how they communicatively manage disease-related uncertainties.

The UMT considers uncertainty a common human experience that can arise due to ambiguous and unpredictable events or insufficient information and suggests that communication is central to the management of uncertainty. ${ }^{11,15}$ In the illness context, uncertainty can arise due to complexity of illness, insufficient and contradictory information, and inability to integrate new information into existing worldviews and belief systems. ${ }^{17,18}$ The theory assumes that individuals evaluate uncertainty for its meanings (i.e., as an opportunity, a danger, or a chronic situation) and that such appraisal and the associated emotional responses (positive, negative, or neutral) determine strategies used to manage uncertainty, including information seeking or avoidance, adaptation, and social support. ${ }^{15}$ Avoidance includes strategies such as distracting oneself from thinking about a health threat, denying that problematic circumstances exist, disengaging from interactions or media that remind one about a threat, and controlling conversations. ${ }^{16}$ It can happen unconsciously (i.e., automatically) or consciously (i.e., nonmechanically) when one wants to disengage from information that is threatening. ${ }^{11}$ Information seeking or avoidance allows individuals to maintain, reduce, or increase uncertainty. ${ }^{16}$

Uncertainty appraised as a danger/threat is associated with emotions such as anxiety or fear, which can be managed by avoiding or seeking information. Conversely, uncertainty appraised as an opportunity can produce feelings of hope and optimism, which can be maintained or increased by information seeking or avoidance..$^{11,15,19}$ Thus, whether information seeking or avoidance is adopted depends on which option provides the most hope ${ }^{20}$ and whether the goal is to reduce, increase, or maintain uncertainty..$^{19} \mathrm{~A}$ recent study by Peng and colleagues ${ }^{21}$ suggested that cancer-related beliefs such as worry, information overload and fatalism can influence individuals' need and preferences for uncertainty management strategies (e.g., information seeking or avoidance), and a meta-analysis of uncertainty and information management in the illness context by Kuang and Wilson ${ }^{22}$ also showed a consistent and positive association between illness uncertainty and information avoidance.

Interpersonal communication about ovarian cancer is a useful context to investigate the relationship between openness, TA, and uncertainty management because of prevalence of TA in communication about ovarian cancer, ${ }^{4,23}$ ubiquity of uncertainty in the ovarian cancer context, ${ }^{1,3}$ and centrality of information seeking and avoidance to uncertainty management. ${ }^{11}$ Thus, the present study analyzed motivations for TA among ovarian cancer patients/survivors, how patients/survivors communicate openly about their cancer experiences with relational others, and how TA serves as an uncertainty management strategy.

This study is significant and unique. First, by investigating uncertainty, openness, and TA together in the specific context of cancer, this study provides evidence for connection among these communication behaviors (i.e., uncertainty, openness, and TA).

Second, the focus on patients' and/or survivors' individual accounts is another way this study contributes to existing scholarship on openness and TA in cancer communication. Although some past studies ${ }^{24,25}$ have included cancer survivors/patients as participants, the majority of research on openness and TA in cancer communication used data from a relational dyad (e.g., a cancer patient and a partner) or caregivers and family members. While the current study recognizes the importance of multiple voices in understanding nuances of the topic, we believe that the perspectives of patients/survivors are sometimes lost when multiple voices are presented. Hence, there is a need to highlight their views to provide a more holistic understanding of openness and TA in communication about cancer.

Further, this study extends the extant literature on openness and TA in cancer communication by focusing on ovarian cancer. Ovarian cancer presents a useful context to examine this topic because, as stated earlier, characteristics of the disease can present communication challenges for those affected. Thus, it is important to understand how patients/survivors manage disease-related uncertainties so that research-driven communication interventions can be designed to better serve that population.

\section{Openness and avoidance in cancer communication}

Openness and avoidant communication are complex communicative behaviors. Goldsmith, Miller and Caugh$\operatorname{lin}^{26}$ define TA as "deciding not to discuss particular issues and/or withholding some details of particular issues" and openness as "disclosure of thoughts, information, and/or feelings" (p. 62). Neither openness nor TA is inherently good or bad, as both forms of communication have benefits and consequences for individual and relational wellbeing. How these benefits and consequences are perceived and the resulting impact on relationships depend on the nature of communication, the communicator, the relationship, and 
the sociocultural context. ${ }^{25}$ Openness and TA are intertwined, such that open communication by an individual (e.g., the cancer patient) can lead to less perceived TA. ${ }^{27}$

Even though most individuals consider open communication a valuable, pro-social behavior, openness is understood differently by different people. ${ }^{28}$ Recent work by Goldsmith and Miller ${ }^{28}$ points to varied iterations and dimensions of open communication by cancer patients and relational partners. Openness varies by topic and individual and changes over time. Goldsmith and Miller ${ }^{29}$ found that among cancer patients and relational partners, some topics were discussed more openly and freely because they are easy to talk about, whereas others were difficult to discuss and are discussed only occasionally. Moreover, some topics (e.g., diagnosis and telling other people about the cancer) might be resolved in a single conversation and thus may not be brought up again, whereas others are discussed when prompted by a situation. For example, treatment decisions are discussed more frequently and openly because they entail mainly facts and medical information; issues related to sex and appearance are discussed less frequently because they are difficult to talk about; death is usually difficult and discussed once (partly because cancer patients and relational partners do not want to upset one another and also because it is difficult to discuss what would happen to their children if the cancer becomes terminal); and topics related to finances, uncertainties, work, and identity are discussed occasionally ${ }^{29}$ Further, as the level of uncertainty about cancer changes, the ensuing level of communication about issues causing uncertainties also changes. ${ }^{29}$ Thus, because of variability in how openness is enacted, scholars suggest talking about degree of openness between a relational pair instead of whether or not they are "open." 28

The level of openness and TA employed in a communication context depends on the situation. For instance, with life-threatening illnesses such as cancer, illness characteristics such as severity, duration and status of recurrence, and the relationship between those affected and relational others can impact enactment and outcomes of openness or TA. ${ }^{26,30}$ Emotional exhaustion and depression resulting from caring for a patient with terminal cancer can also negatively impact how caregivers openly communicate about illness and death. ${ }^{30,31}$ While there is generally low level of TA between cancer patients/survivors and relational others, ${ }^{32}$ when TA occurs, spouses and relational others are more likely to engage in avoidance..$^{32,33}$ Relational others avoid communication due to a multitude of reasons, including self- and other-protection, privacy, to maintain hope and normalcy, when the talk is deemed inappropriate or unnecessary, or due to perceived lack of efficacy in appropriately broaching the topic. ${ }^{25,26,34} \mathrm{Simi}-$ larly, perceived lack of reciprocity and poor prognosis can hinder open communication between survivors and partners about cancer-related topics. ${ }^{34}$

TA can negatively impact relational satisfaction and lead to anxiety and depression in cancer patients/sur- vivors. ${ }^{25,33}$ Topics commonly avoided in the cancer context include information and emotion-laden issues such as prognosis, death and dying, sexuality, and being a burden. ${ }^{32,34,35}$ However, there are differences between survivors and relational others in terms of cancer-related topics avoided. For instance, whereas survivors can openly talk about topics such as death and prognosis, relational others often avoid such topics due to perceived lack of efficacy. ${ }^{34}$ Scholars have drawn on the concept of ownership of private information to explain discrepancy in TA between cancer patients and relational others. They suggest that relational partners perceive cancer patients as primary owners of cancer-related information, hence their hesitation to openly discuss certain issues related to the cancer experience. ${ }^{27,34}$

Existing scholarship on openness and TA in the broader cancer context provides some insights into the nature of communication about ovarian cancer. Some past studies have explained why ovarian cancer patients/survivors avoid disease-specific topics ${ }^{4,23}$ and why the public generally avoids talking about the disease. ${ }^{5}$ However, to our knowledge, there is no known research that examines TA and openness in the ovarian cancer context and how patients/survivors use these communication behaviors to manage disease-related uncertainty. Thus, this study aims to explore the connection between openness, TA, and uncertainty management in the ovarian cancer context and asks these research questions: "How are openness and TA enacted by ovarian cancer patients/survivors during interpersonal communication about their cancer experiences?" and "How are openness and TA uncertainty management strategies relied upon in interpersonal communication about ovarian cancer?"

\section{Materials and Methods}

\section{Participants}

Participants included 28 ovarian cancer survivors in northwest Ohio and southern Michigan in the United States. They ranged in ages from 23 to 84 years (average age was 56). Twenty-seven identified as Caucasian, and one identified as Mexican American. Eleven participants were diagnosed at stage III, six at stages I and II each, three at stage IV, and two were unsure of the stage of disease. The majority of participants were married (18; $64 \%$ ), and they were all heterosexual. Eighteen participants had children (both biological and adopted) and 10 had no children. Eleven (39\%) participants were premenopausal at the time of diagnosis, and 17 (61\%) were post-menopausal. The disease had recurred at least once in eight participants (six of whom were in treatments or about to begin treatments when data were collected); 20 participants had never had a recurrence. One participant had terminal disease and had stopped treatments at the time data were collected. 


\section{Procedure}

After approval for the study was granted by the Bowling Green State University research ethics board (ethics approval number 686884), the first author recruited participants with the help of cancer support organizations in northwest Ohio, including the Cancer Connection of Northwest Ohio and the Ovarian Cancer Connection in Toledo, Ohio. The organizations sent notices about the study including information about an incentive of a \$20 gift card for participation to their mailing lists, and interested women contacted the first author to set up interviews. Over the course of five months (March-August 2015), 28 eligible women contacted the researcher to be interviewed. Women were included in the study if they were at least 18 years old and had been diagnosed and treated for ovarian cancer. Interviews took place at the convenience of participants who provided written consent before the interviews took place. The semi-structured, in-depth interviews ranged in length from 45 to 120 minutes and took place face-to-face (19 participants), over the telephone (8 participants), or via FaceTime (1 participant). The interview guide included open-ended questions such as "When your cancer experience comes up in conversations with family, friends, and acquaintances, how do you talk about it?" and "Do you have any difficulties talking about your cancer experience? If so, what are they?" (See Appendix A for interview guide.)
Interviews were audio-taped and transcribed verbatim for analysis purposes. Data saturation was reached as a result of rich data facilitated by an adequate (i.e., large) and appropriate sample (i.e., knowledgeable informants). ${ }^{36,37}$

Table 1. Examples of codes and categories.

\begin{tabular}{|c|c|c|}
\hline Data Extract & Initial Codes & Categories \\
\hline $\begin{array}{l}\text { We are an open family; we talk about everything. } \\
\text { So we talked about this issue as well and that } \\
\text { really helped. When you get things out in the } \\
\text { open, you're not guessing what people are } \\
\text { thinking. } \\
\text { (Patient/survivor diagnosed at stage III) }\end{array}$ & $\begin{array}{l}\text { 1. Family communicated openly about } \\
\text { everything } \\
\text { 2. Helpful to talk openly about cancer experience } \\
\text { with family } \\
\text { 3. Communicating openly helped clear confusion } \\
\text { and gets everyone on the same page }\end{array}$ & Family communication pattern and openness \\
\hline
\end{tabular}

I can't say I really kept anything from them. I didn't have a lot of side effects from my treatments; whereas if they would have seen me showing a lot of side effects where mom is sick and vomiting, I think it would have been a whole different issue. (Patient/survivor diagnosed at stage II).

I didn't hold back. I would let them know my fears. I don't say too much in front of my children that "I'm scared" or "I'm going to die from this disease," or "it is going to get me." I don't say those things to them because I don't want much sadness in their world as much as possible.

**

There is only a handful of people I feel I can entirely open up to and tell how scared I am; everybody else [my family, my sister] I want to protect them a little bit... It's years of being with them; they are good friends. You show your vulnerability a little bit because you don't feel that you're going to be judged (Patient/survivor diagnosed at stage II)
1. Did not keep anything about cancer experience Treatment side effects and openness from children

2. Talked openly about cancer experience with Audience and level of openness or TA children

3. Having few treatment side effects helped with communicating openly about cancer experience with children

1. Did not hold back anything about her Audience impacted level of openness or TA experience when talking with family

2. Would let family know about her fears about Reason for TA: to protect loved ones did not reveal too much of her fears to her children

3. Wanted to protect children from sadness

**

4. Could be completely open and honest about how she felt with close friends but not with family members.

5. Wanted to protect family members by not being open about every aspect of her cancer experience

6. Being open amounts to being vulnerable
Openness requires vulnerability

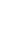


Table 1. Continued from previous page.

\begin{tabular}{|c|c|c|}
\hline Data Extract & Initial Codes & Categories \\
\hline $\begin{array}{l}\text { I didn't discuss my diagnosis with my mom. My } \\
\text { mom has Alzheimer's disease so she still does not } \\
\text { comprehend cancer. } \\
\text { (Patient/survivor diagnosed at stage III) }\end{array}$ & $\begin{array}{l}\text { 1. Did not talk about diagnosis with mom who } \\
\text { has Alzheimer's } \\
\text { 2. Mother's health status impacted level of } \\
\text { openness and TA about cancer experience }\end{array}$ & $\begin{array}{l}\text { Audience and level of openness or TA } \\
\text { Reason for TA: to protect loved ones }\end{array}$ \\
\hline $\begin{array}{l}\text { I never told my mother that I had cancer because } \\
\text { she was still grieving the loss of my brother. I } \\
\text { explained to her that I was going to do D\&C } \\
\text { [dilation and curettage]. Until the day she died I } \\
\text { never told her I had cancer; I just did not see any } \\
\text { point in giving her that. } \\
\text { (Patient/survivor; not sure about disease stage) }\end{array}$ & $\begin{array}{l}\text { 1. Did not talk about diagnosis with mom } \\
\text { 2. Mom lost son and was grieving } \\
\text { 3. Wanted to protect mom by not disclosing } \\
\text { diagnosis } \\
\text { 4. Mother's health status impacted level of } \\
\text { openness and TA about cancer experience }\end{array}$ & $\begin{array}{l}\text { Openness/disclosure will not be beneficial } \\
\text { Reason for TA: to protect loved ones } \\
\text { Audience and level of openness or TA }\end{array}$ \\
\hline
\end{tabular}

I didn't tell them everything in-between because I wanted them to be sophomores and juniors and not worry about their mom dying or anything. **

When I talk to my male co-workers, I tell them about the signs and symptoms and what I went through. I probably am more open with people that don't know me because there's that wall that goes up where I want to protect the people that know me [family]. I guess I assume that since my family was there they know what I went through. They saw what I went through: 25 staples on my stomach; I came home [from hospital] with drainage tubes because I was still draining. But I wanted to be okay to them.

(Patient/survivor diagnosed at stage I)

I don't tell my mom a lot [about my cancer experience]; but if my cancer were to come back again I will tell her. For instance I was told I had a problem with my brain but I won't tell her; my husband knows but I won't tell her. That is my way of protecting her, to shield her.

(Patient/survivor diagnosed at stage III)

We're pretty open; we talk about everything. We talk about the pain, the funeral and everything. Everybody knows what I want, which is good. It is hard too. My parents don't want to talk about some of it which is understandable; I'm their only child and they are in their 80 s; it's really tough on them.

(Patient/survivor diagnosed at stage II)

At first, I wouldn't tell my parents a whole lot about what was going on because I know how bad it hurts them; I felt bad that I was the one who was ill so I kind of tried to protect them. And I remember one day just sitting around and talking with my mom and I was saying "well, if there's any saving grace to this, it is me that has cancer and not one of my girls" and she looked at me and said, "how do you think that I feel?" It was at that moment that I realized that it didn't matter if I was a woman in my 40s; I was still their daughter. So I started letting them in more. I started telling what the doctor said, the good and the bad because I realized that by shutting them out I wasn't helping them.

(Patient/survivor diagnosed at stage III)
1. Did not tell children everything about cancer experience

2. Did not want her cancer experience to interfere Reason for TA: to protect loved ones with children's childhood experiences

3. Talked openly about different aspects of her experience with different people

4. Less open with family about treatment side effects in order to protect them

5. Family went through cancer experience with her and that impacted what aspect of her experience she discussed with them because they supposedly already know
Audience and level of openness or TA
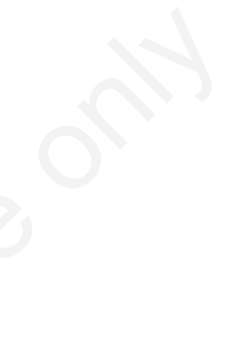

1. Did not disclose everything about cancer Audience impacted level of openness or TA experience to mom

2. Wanted to protect mom

3. Talked openly about different aspects of her experience with different people

Reason for TA: to protect loved ones
1. Family communicates openly about everything Audience impacted level of openness or TA

2. Her parents did not want to talk about her impending death
1. Did not initially disclose everything about her cancer experience with parents

2. Wanted to protect parents

3. Began to be open with parents when she realized that not disclosing was rather hurting them
Openness is a process that begins with TA

Reason for TA: to protect loved ones 
The authors met consistently to deliberate and also to select quotes from participants to illustrate themes. The discussion sessions and use of illustrative quotes from participants helped enhance trustworthiness of the findings. ${ }^{40-42}$ It is important to keep in mind that the data were self-reported by participants; thus, the findings represent the researchers' analytical interpretations of participants' descriptions of the ways they thought they acted and of the reasons they gave for their actions.

\section{Results}

The results showed that for the most part, ovarian cancer patients/survivors communicated openly about disease diagnosis, prognosis, and treatment side effects when talking about their experiences with people in their social net- works. However, the degree to which they were open about their experiences depended on who they were communicating with (i.e., audience), and on the existing patterns of communication with the audience (i.e., reasons for openness). Participants also avoided talking about aspects of their experiences to protect loved ones as uncertainty about disease prognosis increased (i.e., protecting loved ones), when they perceived that the audience for the disclosure was young children or sick/aging parents (i.e., deeming disclosure unbeneficial), and also when they needed to make personal sense of the cancer experience first (i.e., making personal sense of cancer). See Figure 1 for an illustration of the relationship between openness, TA, and uncertainty management. In the sections below, we discuss openness and its sub-themes followed by TA and its sub-themes.

\section{Interpersonal Communication about Ovarian Cancer}

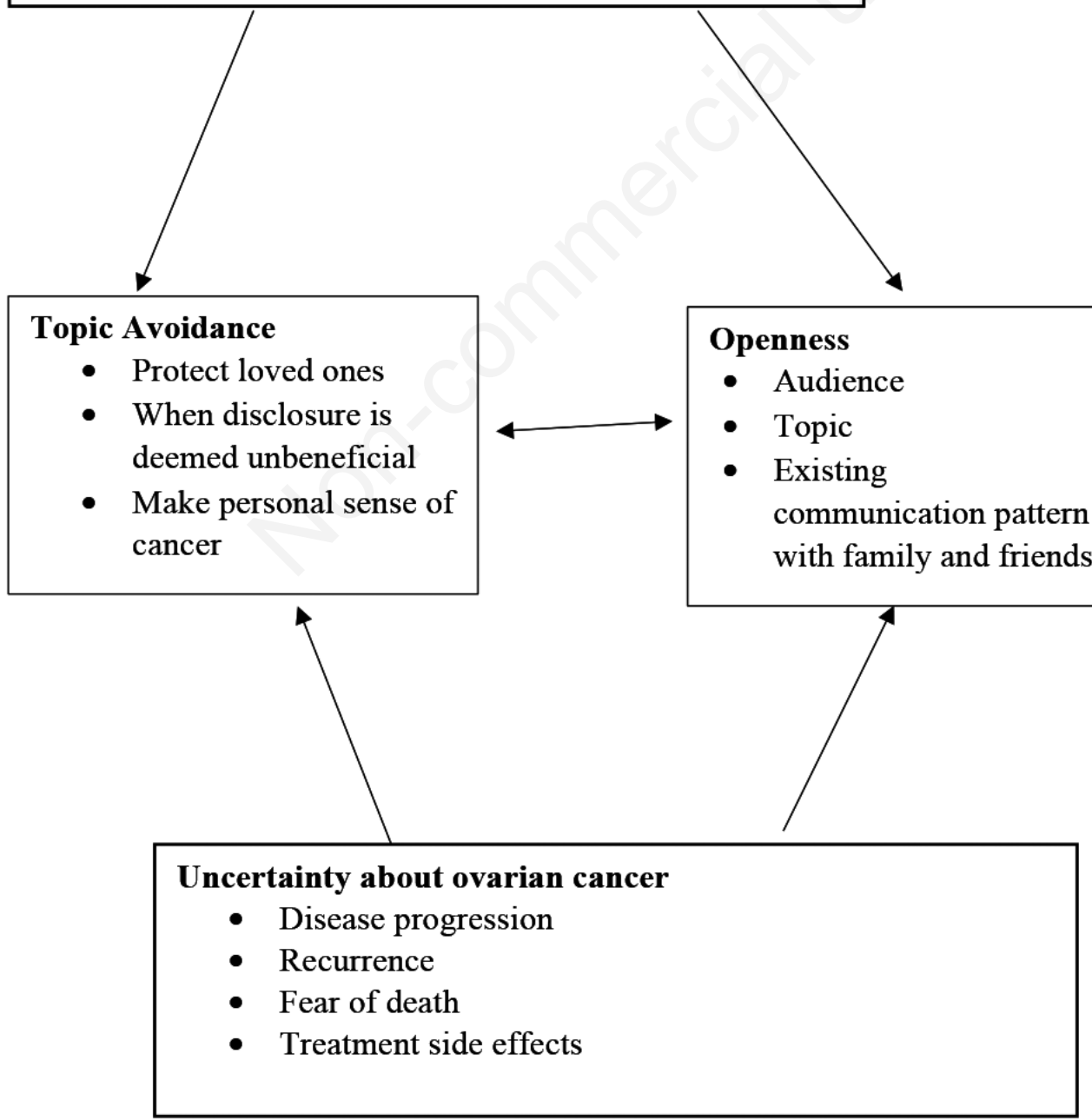

Figure 1. Openness, TA and uncertainty management in interpersonal communication about ovarian cancer. 


\section{Openness}

Participants explained using varied degrees of openness when disclosing thoughts and feelings to other people. This meant that they readily talked about some aspects of their experiences more than others, and they also were more open with some individuals than with others. A combination of issues impacted how open participants were about their experiences.

\section{Tailoring openness to the audience}

Participants negotiated how openly they talked about their experiences depending on the topic they were discussing and whom they were talking to. Participants who responded well to treatments and those with adult children stated that they were very open about the disease's prognosis with their adult children. For instance, a participant who was diagnosed at stage II and whose disease had never recurred noted that she was able to express how she felt because her children were old enough to understand cancer, and she also did not have severe treatment side effects:

Being that the children were older at the time, I know they knew that people die from cancer. I didn't have a lot of side effects from my treatments; whereas if they would have seen me showing a lot of side effects where mom is sick and vomiting, I think it would have been a whole different issue.

Also, another participant who was diagnosed at stage II and had adult children said she waited until a scan confirmed a mass on her ovary before disclosing her diagnosis to her children. She said, "I didn't call them [i.e., children] right away when they found the mass. I waited until I had the CT [computed tomography] scan and it showed that there was a mass on the ovary." This woman's children knew she had problems with her hip and was in physical therapy, but when her family doctor referred her to a gynecologic oncologist, she decided to wait until she knew the diagnosis before telling her children.

Participants with young children also reported communicating openly about the illness, but not "dwelling" on difficult topics such as death. For example, a participant who was living with recurrent ovarian cancer and had two daughters aged 16 and 11 explained being "honest" about the prognosis with her children but not "dwelling on it." She said, "They know the reality of this disease, but I don't dwell on it. I don't sit there and talk about death and dying or anything like that." Openly discussing less emotionally-laden topics and purposefully avoiding emotionally-dense ones was the communication strategy this woman adopted because "the children saw me very, very ill on some days where I couldn't get out of bed." She said each time the disease recurred, she avoided dwelling on the possibility of dying when talking to her children; instead, she tried "to be more present in their [her daughters'] lives and more aware of everything that's going on." Along similar lines, another participant who was diagnosed at stage III described her cancer as "peas" for her nine-year-old son who was too young to understand a cancer diagnosis:

We did not want to call it "cancer" in front of my smallest child who was nine years old. We told him that I just had some infections in my stomach, and I am going to have surgery, and it is going to make mom's hair fall off. We did not call it "cancer," so we thought of something that I really do not like and I hate peas so we called it "peas." Mom has peas.

This participant said when the doctor was explaining the diagnosis and treatments to her, all she could think about was how to disclose the news to her three children, aged 21, 15 , and nine because "When kids are young and they hear 'cancer,' they immediately think that somebody has died." She explained further that when she was undergoing treatments, "I didn't want my children to see me sick; so I never allowed it. I made sure I got up every day, took a shower, and put make-up on even though I wasn't working."

Further, seven participants mentioned that they talked openly about disease facts, including symptoms and treatment side effects, with acquaintances and co-workers to educate them about the disease, but did not discuss these issues with family members because of an assumption that they already knew these facts by witnessing participants' experiences. For instance, one woman explained:

When I talk to my co-workers, I tell them about the signs and symptoms [of the disease] and what I went through. I probably am more open with people that don't know me. I guess I assume that since my family was there, they know what I went through.

Another participant also stated using a similar strategy when discussing her experience:

I tell them [i.e., acquaintances] about the worst moments of my life at the time, not to exaggerate though, because I want to wake them up. But the people around me [i.e., family and close friends] do not have to be reminded because they have seen it.

Similarly, another woman explained, "I express more facts to people whom I don't know and weren't with me throughout my experience; but with family and friends, it's an emotional conversation."

A different participant also said she would "add emotions and show my vulnerable side" when recounting her cancer experience to her best friends. This woman's friends missed specific details about her cancer experience because they lived far away and did not go through the diagnosis and treatment experience with her: 
They don't know those details like driving to a radiation and having to pull to a side of the road to throw up and then continuing to finish that drive; they don't know because they did not experience that with me.

This participant had relocated to a new city to take care of her mother, who passed away a few months before the participant's diagnosis. Her example suggests that participants sometimes left out some details about their cancer experience not on purpose, but because those details had to be experienced in the moment.

Additionally, 20 participants explained that they "read" their audience to determine how much information to share. For instance, one woman said:

My next-door neighbors could have cared less. They see me walking the dogs and ask how I'm doing; they know I have ovarian cancer but don't want to know more... I try to read people to figure out if they want to know more; they might not.

This woman also explained that when she complained about a treatment side effect of neuropathy making it impossible for her to return to work, her friend retorted, "What do you care? You're alive!" She said from then on, she only shared specific details about her experience with people who genuinely wanted to know. Another woman, who was diagnosed at stage II, said when talking about her cancer experience with people, she usually provided general information, "and if they want to know anything [in detail] I tell them what happened." One more participant, diagnosed at stage III, also mentioned that she used people she was communicating with as a "cue or guide" to determine how much to disclose because "some people don't want to know all the gory details" of her experience.

\section{Reasons for openness}

It was also evident from participants' narratives that the degree to which they were open about their experiences depended on issues such as existing patterns of communication in families. Participants whose families communicated openly about issues expressed holding nothing back when discussing their cancer experiences with family members. For example, one participant noted, "We are an open family; we talk about everything. So we talked about this issue as well and that really helped. When you get things out in the open, you're not guessing what people are thinking." This woman, who was diagnosed at stage III, openly discussed all aspects of her experience with her family in order to quell speculations about what was unknown about the disease. She mentioned that she and her husband also discussed with her adult children the possibility of her dying from the disease. Another participant also stated that she shared the same details about her experience with everyone to keep her story consistent:
I decided I would be transparent about it. I didn't want to be in a situation where I had to keep track of what I told my parents and my best friends; I just told the same story to everybody.

This woman was single and lived alone during her treatments.

Conversely, family communication patterns were also a reason for TA where family members avoided discussing participants' cancer experiences in line with informal family disclosure rules and also because participants did not want the topic to be discussed. Such was the case with one woman diagnosed at stage I who said she could not remember:

One instance that it [her cancer ordeal] ever came up in conversations or that my sons ever said a word about it since it happened; I don't think my husband even ever said a word about it since it happened.

She explained that her family approached her cancer experience in that manner because she herself did not want to talk about it: "They know me. Mom says this is the way it is, and we move on."

It is worth noting that although all participants considered their families as open communicators, it was clear from their narratives that they carefully disclosed their diagnosis, prognosis, and treatment side effects taking into consideration the ages of children, appropriateness of location and time, and health states of other members of the family, including aging parents.

Another issue that encouraged openness was when participants felt a sense of space and freedom to be vulnerable while being open. Participants explained that they needed a non-judgmental space to express themselves because openly discussing their feelings and fears made them vulnerable. Some of them found this space in close friends, but not family members, because they wanted to protect their families. For example, a participant who was diagnosed at stage II disclosed that:

There is only a handful of people I feel I can entirely open up to and tell how scared I am. It's years of being with them; they are good friends. You show your vulnerability a little bit because you don't feel that you're going to be judged.

Another participant with a stage III diagnosis also said she talked more to her close friend who also had cancer because "She's gone through it and she's going through it again so she knows what it is like; unlike someone who knows someone who has cancer, they [i.e., people who have not personally experienced cancer] are more judgemental." Relatedly, a participant who had terminal disease acknowledged that communicating openly about her 
death was crucial in helping her family know and honor her wishes; however, her impending death was a difficult subject for her parents:

We're pretty open; we talk about everything. We talk about the pain, the funeral and everything. Everybody knows what I want, which is good. It is hard, too. My parents don't want to talk about some of it which is understandable; I'm their only child and they are in their $80 \mathrm{~s}$; it's really tough on them.

As these examples reveal, it was not a single issue (e.g., audience or family communication pattern) that motivated participants to be open about their experiences; instead, they considered multiple issues together to decide how much to disclose about specific aspects of their cancer experiences.

\section{Topic avoidance}

Several participants explained their decision not to discuss certain aspects of their cancer experiences with young children or elderly and/or sick parents. In addition to that, participants who were uncertain about their prognosis because of recurrences or late diagnosis (i.e., stages III or IV) tended to avoid disclosure of their feelings concerning the issue; some also limited disclosure the more the disease recurred. Reasons participants gave for avoiding communication are discussed below.

\section{Protecting loved ones}

In order not to further distress loved ones, especially children, 10 participants said they withheld some details about their cancer experiences. As noted above, one woman wanted to protect her children and thus did not divulge every detail about how she felt to them:

I don't say too much in front of my children that "I'm scared" or "I'm going to die from this disease," or "It is going to get me." I don't say those things to them because I don't want much sadness in their world as much as possible. As a mother, you're protecting till you're gone. But I know I am not fooling them; I know that.

Uncertainty about progression of disease and what that meant for her life and her children contributed to this participant's reluctance to fully disclose her feelings to her children. She was diagnosed at stage II, had three recurrences, and considered herself "stage IV now because it [cancer] has metastasized to my liver." She added, "I can see the frustration [in her children] each time the disease is back. My son keeps saying 'you fight, mom; you keep fighting' and my daughter also wants me to fight." She said her daughter was not yet married, so she had been "bargaining" with God to "please make sure that my daughter meets somebody special before I die because I'm so afraid that she will be by herself when I'm not around. That's my biggest fear." This quote suggests that uncertainty about how the disease was developing, concern about the devastation it would cause her children to know her fears, and fear about how life would be for her children when she died all contributed to this woman's decision to protect her children by not disclosing information that would distress them.

Another participant also explained the reason for not disclosing everything about her experience to her children as follows:

I didn't tell them everything in-between because I wanted them to be sophomores and juniors and not worry about their mom dying or anything. I don't regret it because I would not have ever wanted them to not do something with their friends or stay home because they felt sorry for me.

This participant admitted that because she did not fully disclose her illness experience to her children, she had missed opportunities to receive support from them. It was later, when she participated in an ovarian cancer awareness walk with her family, that her children got a glimpse into her experience. She recalled, "All four of the kids said 'We have no idea; you came home and said 'I have cancer and I'm going to have surgery' and later you said 'I'm better." Although this woman did not explicitly state this as a reason for not telling her children every detail about her cancer experience, uncertainty about nature of the disease may have contributed to issues she avoided talking about with her children. Her ovarian cancer cell was rare (i.e., juvenile granulosa cell tumor), and there were many things about the disease neither she nor the doctors could control or predict. For instance, she said: "I've had four different masses pop up on my abdomen and my pelvic side-wall, but they all came back benign," and:

My numbers [for inhibin A and B, a type of ovarian cancer tumor marker] went up to 42 , but there was nothing that showed on the PET [positron emission tomography] scan, and they [doctors] said my cell is known for micro-tumors, so they lay dormant, and you can't find them. So I'm just at a point where I have to wait until the cells get big enough where they can find it.

Because of these issues, she said she "just never let them [children] in that far" on her experience.

Similar to these examples, another woman also avoided discussing details about her illness to protect her parents. However, following a conversation with her mother, she realized that keeping information away from her parents was creating more uncertainty and anxiety for them and, thus, began to be more open with them: 
At first, I wouldn't tell my parents a whole lot about what was going on because I know how bad it hurts them; I felt bad that I was the one who was ill so I kind of tried to protect them. And I remember one day just sitting around and talking with my mom, and I was saying "Well, if there's any saving grace to this, it is me that has cancer and not one of my girls" and she looked at me and said, "How do you think that I feel?" It was at that moment that I realized that it didn't matter if I was a woman in my 40s; I was still their daughter. So I started letting them in more. I started telling what the doctor said, the good and the bad, because I realized that by shutting them out I wasn't helping them.

This example points to open communication as a process that sometimes begins with avoidance. Avoiding certain details about her experience gave this participant the chance to gauge her own feelings and anticipate how her parents would react; she later opened up when she was sure the topic was something her parents wanted to know.

\section{Deeming disclosure unbeneficial}

Similarly, when participants determined that communicating about their experiences would not be beneficial to the people they were communicating with, they chose not to disclose. For example, one woman said she did not disclose her diagnosis to her mother who had Lewy body disease, was in a nursing home, and was still grieving the loss of her brother. She did not want to further burden her mother who was already emotionally distraught:

I never told my mother that I had cancer because she was still grieving the loss of my brother. I explained to her that I was going to do $\mathrm{D} \& \mathrm{C}$ [dilation and curettage]. Until the day she died, I never told her I had cancer; I just did not see any point in giving her that.

Another participant also stated she did not tell her mother about her stage III diagnosis because her mother was not in a position to understand. She explained, "My mom has Alzheimer's disease, so she still does not comprehend cancer." Both women determined that disclosing their diagnosis would not yield the needed support from their mothers and would also not benefit the mothers who were not in a position to mentally process the news.

At first glance, it may appear the health conditions of their mothers were the reason these participants did not disclose their diagnosis, but a deeper look at their cases showed that the cancer diagnosis did not fit into the worldviews of both women, leading to uncertainty. Uncertainty in illness can arise due to inability to integrate new information into existing worldviews and belief systems, according to existing research. ${ }^{17}$ For instance, the first woman explained issues going on in her family at the time she was diagnosed, including death of her brother from bladder cancer and her mother's diagnosis with Lewy body disease, and how doctors initially did not think her symptoms indicated ovarian cancer: "It was quick how I was diagnosed. I found that it was ovarian cancer and then it was gone [i.e., had surgery to remove tumor]; so it wasn't like I had any time to even think about it." She had surgery, but not chemotherapy, and was back to her regular schedule one week after her surgery. Similarly, the second woman described her life as "very full" from taking care of her mother, working part-time in the evenings, and volunteering for several organizations, adding that "I'm too busy to sit and worry about how I am going to cope." Thus, she had challenges integrating this new information (i.e., a cancer diagnosis) into her plans and schedule.

Another participant who was diagnosed during her teen years said she did not disclose her anger and frustrations to anyone because that was something she needed to figure out on her own. She described that period in her cancer experience as a "reflective stage" and "a big critical thinking point for me." She explained that although she was very close to her mother and talked to her to process her diagnosis and treatments, she still "internalized a lot of [her anger]. I tried to get emotions out by doing physical activities and things that made me feel like I used to be."

\section{Making personal sense of cancer}

Uncertainty about cancer prognosis led 12 participants to withhold information about their experiences until they could manage some of that uncertainty on their own. For example, one woman likened her cancer diagnosis and treatments to an unfamiliar experience which she needed to understand on her own before she could express to others. She said she did not want to talk to people when she was initially diagnosed at stage III 'because you're just crawling up a hole and when you're out of that hole, then maybe you can communicate with some people." This participant eventually started letting people back into her life when her treatments were over and recently went to lunch with a friend she had refused to see when she was in treatment: "When I received news of my diagnosis, until I was done with treatments, I became a hermit and very quiet... I changed into a totally different person." Similarly, another participant who was living with recurrent ovarian cancer and had to take medical retirement due to complications from treatments said that before she returned to work after her primary treatment, she "sent a letter to my [work] colleagues letting them know that I would answer any question about ovarian cancer they needed to know; I just don't want questions about prognosis because I don't know what my prognosis was." She said setting those "boundaries" was necessary to foster conversation about her experience by focusing on topics she felt comfortable talking about. Another woman who 
was also living with recurrent disease said she refrained from talking about her experience publicly the more the cancer recurred: "The more the cancer comes back, the more I become a little inward because there is a feeling that 'It has got me; it is going to take my life eventually."'

Further, TA by participants was impacted when family members avoided communicating about issues pertaining to participants' cancer experiences because of their own uncertainties about the disease. For example, one participant mentioned how uncertainty about outcome of treatments made her mother unwilling to communicate. Her mother later opened up when she felt positive about treatments:

She at first put like a wall up; she wouldn't come to the hospital when I had my surgeries because she didn't want to deal with it. But about a year later, you kind of saw this wall come down to where she would ask if she could go to my doctor's appointments with me.

This participant explained that her mother's unwillingness to discuss her cancer experience caused her [participant] to also not broach the topic. She explained how she used her experience to encourage co-workers, friends, and family members to pay attention to their bodies and report any changes to their physicians, but did not have that conversation with her mother because "it was kind of making her [mother] mad." Similarly, as stated earlier, the participant with terminal disease communicated openly to most people about her impending death, but not with her father who had difficulties talking about the topic:

Because I'm the only child and we've been very, very close, he has a very hard time dealing with my situation. So it's easier for him to get up and go to the other room or go outside and do something than to sit down and talk to me because he can't deal with my death, which makes sense. My mom is a little bit better, but she is on anti-depressants. But at least we can talk about it.

This participant mentioned that when she was initially diagnosed, "I was pretty optimistic that they [doctors] could get it and I would be better again" and that even though her family was "devastated and scared" by the diagnosis, they "were pretty optimistic too." However, they lost hope "after the first chemotherapy failed and the cancer started to grow again within 30 days after I stopped treatment" and subsequent treatments were also not effective. Thus, the changing trajectory of this woman's illness impacted her pattern of communication about her experience with her family - from being hopeful about treatments to accepting that treatments were not working and then talking about her impending death.

These examples suggest that participants' enactments of openness and TA about their experiences changed rel- ative to the changing illness trajectory: While some of them would not discuss death openly as the disease progressed and others were avoidant when initially diagnosed but began to open up once treatments were over, the participant with terminal disease talked openly about death when she knew her cancer was terminal and treatments were no longer effective.

\section{Discussion and implications}

The present study examined openness and TA in interpersonal communication about ovarian cancer in an attempt to address a gap in research on the topic. The findings shed light on how ovarian cancer patients/survivors enacted openness and TA about their experiences and how TA helped them manage uncertainty about the disease. Uncertainty about disease prognosis and effectiveness of treatments prompted ovarian cancer patients/survivors to avoid discussing certain topics. Consistent with uncertainty management theory, uncertainty appraised as a threat/danger is managed by information avoidance - including avoiding specific topics, situations, or selectively attending to information ${ }^{11}$ - findings from this study showed that patients/survivors appraised uncertainties surrounding ovarian cancer diagnosis and treatments as threats and consequently managed these by avoiding topics that promoted these uncertainties. Participants mainly avoided disclosing details about how they felt during treatments and their fears about recurrence and death to children and elderly parents - individuals with whom they had protective relationships. This finding shows influences of the mothering role on communication about ovarian cancer. Many participants desired to openly communicate their feelings; however, they also wanted to protect loved ones similar to the sense of responsibility mothers feel toward their children, and when these goals conflicted, they chose to protect their loved ones by disclosing just enough, but not everything. This is consistent with past research suggesting that negotiating roles as mothers and cancer survivors/patients can be challenging for some women ${ }^{43}$ and that some cancer patients do not disclose their diagnosis to young children and elderly parents in an effort to protect them. ${ }^{44,45}$

Further, the findings suggest that communication about ovarian cancer is layered with degrees of openness and avoidance. It was not an either-or situation, where women were either open or avoidant when communicating about their cancer experiences. Rather, with the same topic, they could be open and avoidant at the same time, depending on the audience, or they could be open at one time and avoidant later and vice versa. For example, whereas women were honest about their feelings (e.g., fear of death or recurrence) with their spouses, they refrained from sharing these feelings with their children. Also, some women avoided certain topics, including prognosis and the possibility of death, during early stages of 
the cancer experience, but became more open about such topics later on as treatments progressed successfully. On the other hand, those who were very open at diagnosis tended to avoid such topics the more the disease recurred.

These findings show openness in ovarian cancer communication as a process that may begin with TA and TA as sometimes being influenced by uncertainty about disease progression. Openness is also determined by a combination of factors, including audience and family communication patterns. Consistent with past research, ${ }^{34,46}$ participants considered not only their own emotions, but also how loved ones would react when deciding how much to disclose about their cancer experiences. These findings are also similar to previous research suggesting that open communication in the cancer context varies by topic, by individual, and over time ${ }^{29}$ and that openness is best conceptualized in terms of variability instead of whether or not cancer patients or relational others are open..$^{28}$

The present study extends past studies by adding the perspectives of ovarian cancer patients/survivors and how uncertainty about the disease impacts enactments of openness and TA. However, contrary to past research suggesting that TA about death increases as prognosis worsens, ${ }^{25,34}$ findings from this study demonstrate that that is not always the case. Whereas some participants avoided openly talking about death as the disease progressed, the participant with terminal disease communicated openly about her death with her family.

The findings provide support for $\mathrm{UMT}^{19}$ by suggesting that as the illness trajectory and levels of uncertainty changed, disclosure patterns also changed. Ovarian cancer is shrouded in uncertainty, and uncertainty management is integral to the illness experience. How women respond to continually changing physical, social, and financial realities of the disease manifests in how they communicate about the disease, including what information - and how much information - is disclosed. This indicates that communication about the disease and uncertainty management strategies are interconnected. This fluidity of communication about ovarian cancer relative to changing illness trajectory supports past research results which showed that as uncertainties and fears change along the cancer trajectory, ensuing levels of communication also change..$^{29}$

The finding about communication challenges between the participant with terminal cancer and her father reflects past studies that relational others are sometimes uncomfortable listening to patients' open communication about cancer-related topics such as death. ${ }^{28}$ Venetis et al. ${ }^{27}$ observed that greater patient openness could lead to greater partner burden (i.e., negative feelings and guilt). Given that death is the most difficult topic to discuss in the cancer context, ${ }^{29}$ intervention efforts should focus on helping cancer patients/survivors and relational others practice sensitivity when discussing death and dying.

These findings have important theoretical and prac- tical implications. Goldsmith and colleagues ${ }^{26}$ explain openness and avoidance as facilitating fundamental communication processes such as privacy regulation, uncertainty management, and information seeking and provision; building on that theoretical position, the present study analyzed how openness and TA informed uncertainty management strategies for ovarian cancer patients/survivors. Also, by examining how openness and TA served uncertainty management purposes for ovarian cancer patients/survivors, this study provides support for a tenet of the UMT that information/communication avoidance is a strategy for managing uncertainty. ${ }^{11}$

Findings from this study point to complexity of interpersonal communication about the uncertain progression of ovarian cancer. Thus, more research on the nature of interpersonal communication about the disease can help generate theory-driven resources to educate affected individuals and families on ways to effectively communicate at different stages of the illness. Similarly, practitioners should incorporate discussions about the interpersonal aspect of the disease, including nuances of openness and TA and how these constructs are related to uncertainty management during counseling sessions and at follow-up visits. This will encourage ovarian cancer patients/survivors and relational others to recognize the importance of these issues to the experience of the disease.

\section{Limitations}

A limitation of this study is the absence of perspectives of relational others. Future studies could include the views of spouses, parents, children, and co-workers to help better understand how openness and TA are interpreted, negotiated as well confronted and controlled in communication relationships with different audiences. Another limitation is that openness and TA were not the primary focus of the interviews; thus, specific details about the topic may have been missed. Additionally, the study population comprised mainly of married, Caucasian, Christian, and heterosexual women. This is a limitation because these social identities placed participants in a privileged position, which was reflected in how they made sense of and communicated about their experiences; therefore, the stories presented in this study may not accurately represent the experiences of ovarian cancer patients/survivors from marginalized backgrounds, including racial, sexual, and religious minorities. Other limitations include a relatively small study population, self-reported and cross-sectional (not longitudinal) data, and interview transcripts not validated by the second author. These limitations notwithstanding, this study provides significant insights into uncertainty management and interpersonal communication about ovarian cancer. 


\section{Conclusions}

This study examined openness and TA in interpersonal communication about ovarian cancer. The results showed that uncertainties about the disease impacted how ovarian cancer patients/survivors communicated about their experiences to protect loved ones and make personal sense of the disease, among other reasons. This suggests that interpersonal communication about ovarian cancer (e.g., openness and TA) and uncertainty management strategies are interconnected. The findings also showed that it is not always the case that TA about death increases as cancer prognosis worsens, as claimed by past research findings; instead, some ovarian cancer patients/survivors avoided openly talking about death as the disease progressed, but others (e.g., a participant with terminal disease) communicated openly about their impending death with family members. These findings shed light on interpersonal communication about the disease and will be useful for scholars, practitioners, patients/survivors of gynecological cancers, loved ones, and caregivers.

\section{References}

1. Howell D, Fitch MI, Deane KA. Impact of ovarian cancer perceived by women. Cancer Nurs 2003;26:1-9.

2. Markman M, Malviya V. An example of ovarian cancer as a 'Chronic Disease Process' - 11-year survival with multiple treatments for recurrent and progressive disease. Case Rep Oncol 2008;1:1-4.

3. Ozga M, Aghajanian C, Myers-Virtue S, et al. A systematic review of ovarian cancer and fear of recurrence. Pall Supp Care 2015;13:1771-80.

4. Reb AM. Transforming the death sentence: Elements of hope in women with advanced ovarian cancer. Oncol Nurs Forum 2007;34:E70-E81.

5. Holmes MS. Pink ribbons and public private parts: On not imagining ovarian cancer. Lit Med 2006;25:475-501.

6. Tetteh DA. Visibility of the ovaries and breasts: An analysis of Angelina Jolie's medical announcements. Fem Med Stud 2019;19:651-66.

7. Kyriacou J, Black A, Drummond N, et al. Fear of cancer recurrence: A study of the experience of survivors of ovarian cancer. CONJ 2017;27:236-42.

8. Manne S, Myers S, Ozga M, et al. Holding back sharing concerns, dispositional emotional expressivity, perceived unsupportive responses and distress among women newly diagnosed with gynecological cancers. Gen Hosp Psychiatry 2014;36:81-7.

9. Cesario SK, Nelson LS, Broxson A, Cesario AL. Sword of Damocles cutting through the life stages of women with ovarian cancer. Oncol Nurs Forum 2010;37:609-17.

10. Lobchuk MM, Bokhari SA. Linkages among empathic behaviors, physical symptoms, and psychological distress in patients with ovarian cancer: A Pilot study. Oncol Nurs Forum 2008;35:808-14.

11. Brashers DE, Neidig JL, Haas SM, et al. Communication in the management of uncertainty: The case of persons living with HIV or AIDS. Commun Monogr 2000;67:63-84.
12. Vevea NN, Miller AN. Patient narratives: Exploring the fit of uncertainty-management models of health care. Rev Commun 2010;10:276-89.

13. Miller LE. Uncertainty management and information seeking in cancer survivorship. Health Communication 2014;29:233-43.

14. Dean M, Davidson LG. Previvors' uncertainty management strategies for hereditary breast and ovarian cancer. Health Commun 2018;33:122-30.

15. Brashers DE. Communication and uncertainty management. J Commun 2001;51:477-97.

16. Barbour JB, Rintamaki LS, Ramsey JA, Brashers DE. Avoiding health information. J Health Commun 2012;17: 212-29.

17. Babrow AS, Hines SC, Kasch CR. Managing uncertainty in illness explanation: An application of problematic integration theory. In Whaley BB (ed). Explaining illness: Research, theory, and strategies. Routledge, 2000:41-67.

18. Parry C. Embracing uncertainty: An exploration of the experiences of childhood cancer survivors. Qual Health Res 2003;13:227-46.

19. Brashers DE. A theory of communication and uncertainty management. In Whaley BB, Samter W (eds). Explaining communication: Contemporary theories and exemplars. Routledge, 2007:201-18.

20. Carcioppolo N, Yang F, Yang Q. Reducing, maintaining, or escalating uncertainty? The development and validation of four uncertainty preference scales related to cancer information seeking and avoidance. J Health Commun 2016;21:979-88.

21. Peng W, Carcioppolo N, Occa A, et al. Feel worried, overloaded, or fatalistic? The determinants of cancer uncertainty management preferences. Health Communication 2021;23: 347-60.

22. Kuang K, Wilson SR. A meta-analysis of uncertainty and information management in illness contexts. J Commun 2017;67:378-401.

23. Lobchuk MM, Bokhari SA. Linkages among empathic behaviors, physical symptoms, and psychological distress in patients with ovarian cancer: A Pilot study. Oncol Nurs Forum 2008;35:808-14.

24. Manne S, Myers S, Ozga M, et al. Holding back sharing concerns, dispositional emotional expressivity, perceived unsupportive responses and distress among women newly diagnosed with gynecological cancers. Gen Hosp Psychiatry 2014;36:81-7.

25. Donovan-Kicken E, Caughlin JP. A multiple goals perspective on topic avoidance and relationship satisfaction in the context of breast cancer. Commun Monogr 2010;77:231-56.

26. Goldsmith DJ, Miller LE, Caughlin JP. Openness and avoidance in couples communicating about cancer. Commun Yearb 2007;31:62-115.

27. Venetis MK, Magsamen-Conrad K, Checton MG, Greene K. Cancer communication and partner burden: An exploratory study. J Commun 2014;64:82-102.

28. Goldsmith DJ, Domann-Scholz K. The meanings of "Open Communication" among couples coping with a cardiac event. J Commun 2013;63:266-86.

29. Goldsmith DJ, Miller GA. Conceptualizing how couples talk about cancer. Health Commun 2014;29:51-63.

30. Stone AM, Mikucki-Enyart S, Middleton A, et al. Caring for a parent with lung cancer. Qual Health Res 2012;22:957-70.

31. Bachner YG, Carmel S. Open communication between caregivers and terminally ill cancer patients: the role of care- 
givers' characteristics and situational variables. Health Commun 2009;24:524-31

32. Shin DW, Shin J, Kim SY, et al. Family avoidance of communication about cancer: A dyadic examination. Cancer Res Treat 2016;48:384-92.

33. Yu Y, Sherman KA. Communication avoidance, coping and psychological distress of women with breast cancer. J Behav Med 2015;38:565-77.

34. Venetis MK, Greene K, Checton MG, Magsamen-Conrad $\mathrm{K}$. Decision making in cancer-related topic avoidance. J Health Commun 2015;20:306-13.

35. Caughlin JP, Mikucki-Enyart SL, Middleton AV, et al. Being open without talking about it: A rhetorical/normative approach to understanding topic avoidance in families after a lung cancer diagnosis. Commun Monogr 2011;78:409-36.

36. Morse JM. "Data were saturated...". Qual Health Res 2015;25:587-8.

37. Morse JM. The significance of saturation. Qual Health Res 1995;5:147-9.

38. Braun V, Clarke V. Using thematic analysis in psychology. Qual Res Psychol 2006;3:77-101.

39. Hsieh H, Shannon SE. Three approaches to qualitative content analysis. Qual Health Res 2005;15:1277-88.
40. Morse JM, Barrett M, Mayan M, et al. Verification strategies for establishing reliability and validity in qualitative research. Int J Qual Methods 2002;1:13-22.

41. Carlson JA. Avoiding traps in member checking. Qual Rep 2010;15:1102-13.

42. Tracy SJ. Qualitative Quality: Eight "Big-Tent" criteria for excellent qualitative research. Qual Inq 2010;16:837-51.

43. Dorgan KA, Hutson SP, Duvall KL, et al. Connecting place to disease and gender: Cohabitating morbidities in narratives of women cancer survivors in Southern central appalachia. Women's Stud Commun 2014;37:292-312.

44. Asbury N, Lalayiannis L, Walshe A. How do I tell the children? Women's experiences of sharing information about breast cancer diagnosis and treatment. Eur J Oncol Nurs 2014;18:564-70.

45. Van Humbeeck L, Dillen L, Piers R, et al. Cancer patients' experiences of communicating and dealing with their older parents: A qualitative study. Eur J Oncol Nurs 2019;38:98103.

46. Charmaz K. Translating graduate qualitative methods into undergraduate teaching: Intensive interviewing as a case example. Teach Sociol 1991;19:384. 